\title{
Radiation therapy for squamous cell carcinoma of the subglottic larynx
}

\author{
Richard Cassidy • Christopher G. Morris • \\ Jessica M. Kirwan • Robert J. Amdur • \\ William M. Mendenhall
}

Received: 8 May 2012 / Accepted: 2 July 2012 /Published online: 18 July 2012

(C) Springer-Verlag 2012

\begin{abstract}
Objective This study aims to summarize our institution's experience in treating patients with primary subglottic squamous cell carcinoma (SCC) with radiotherapy (RT) and to define the optimal treatment plan for these patients.

Methods We retrospectively reviewed the medical records of 18 patients with subglottic SCC curatively treated with RT between 1977 and 2009. $\mathrm{T}_{1}$ and $\mathrm{T}_{2}$ cancers were considered early disease; $\mathrm{T}_{3}$ and $\mathrm{T}_{4}$ lesions were considered advanced disease. Patients were stratified according to whether they received RT alone or RT and surgery. Patients treated surgically tended to have more advanced disease and required a total laryngectomy. Patients were excluded if they had distant metastasis at diagnosis or if their tumor was glottic in origin and extended inferiorly into the subglottis. Results Twelve patients (67\%) had advanced disease, and six patients $(33 \%)$ had early disease. Local control was achieved in $100 \%$ of the patients with early disease, regardless of treatment group. Of the patients with advanced disease, local control was achieved in five of the seven patients $(71 \%)$ treated with RT alone and in four of the five $(80 \%)$ treated with surgery and RT. Ultimate local control was achieved in six of the seven patients $(86 \%)$ with advanced disease treated with RT alone. Overall local control was $83 \%$ at 5 years, with a 5 -year cause-specific survival of $66 \%$ and a 5-year overall survival of $44 \%$. Local-regional control mirrored that of local control, with an overall local-regional control rate of $83 \%$. No patient suffered a severe acute or late complication or acute toxicity during the treatment process.
\end{abstract}

R. Cassidy • C. G. Morris · J. M. Kirwan • R. J. Amdur

W. M. Mendenhall $(\bowtie)$

Department of Radiation Oncology, College of Medicine,

University of Florida,

2000 SW Archer Rd., PO Box 100385, Gainesville,

FL 32610-0385, USA

e-mail: mendwm@shands.ufl.edu
Conclusion Patients with SCC of the subglottic larynx have a high likelihood of local-regional control after undergoing RT along or combined with surgery. Those with $T_{1}-T_{2}$ and low volume $T_{3}-T_{4}$ cancers have high probability of local control with voice preservation after definitive RT.

Keywords Radiotherapy · Outcomes · Subglottis ·

Squamous cell carcinoma

\section{Introduction}

The definition, incidence, diagnosis, management, and treatment outcomes of subglottic squamous cell carcinomas (SCCs) have varied widely in modern literature, likely because these cancers are relatively rare, accounting for between 1 and $5 \%$ of all laryngeal malignancies [1-3]. It is difficult to determine the incidence of primary subglottic SCC since some studies have included lesions originating from the glottis [4], which should be classified as primary glottic cancers. As such, more recent reports have indicated even lower incidences, some as low as $0.2 \%$ of laryngeal cancers [5], by not including glottic tumors that extend into the subglottis. In regards to histology, it is thought that approximately two thirds of all subglottic neoplasms are SCCs.

The larynx is divided into three distinct anatomical regions: the supraglottis, the glottis, and the subglottis. The borders of these anatomic regions have varied in the literature. It is generally accepted that the inferior border of the subglottis is the lower margin of the cricoid cartilage; however, the superior border has been defined in several ways. The definition of the superior border of the subglottis has included: $1 \mathrm{~cm}$ below the apex of the laryngeal ventricle, the inferior border of the true vocal cords, the upper limit of 
the conus elasticus, and $5 \mathrm{~mm}$ below the free edge of the true vocal cords.

The diagnosis of primary subglottic tumors is often delayed because they are generally asymptomatic in earlier stages. Additionally, because there is very little tissue between the mucosa and the cricoid cartilage, cartilage invasion and penetration through the cricothyroid membrane can occur early in the disease course. Once the tumors become more locally advanced, the most common presenting symptoms are hoarseness due to glottic invasion and stridor due to airway obstruction. Computed tomography (CT) with contrast is necessary to define the inferior extent of the tumor. CT is also used to assess for cartilage invasion, lymph node metastases, and extralaryngeal spread. SCCs of the subglottic larynx are staged according to the American Joint Committee on Cancer (AJCC) staging system [6]. The AJCC staging system for the subglottic larynx cancers is similar to the staging system used for glottic and supraglottic SCCs. The management of subglottic SCCs is controversial with some authors reporting favorable outcomes after RT alone, while others have reported poor outcomes and favor surgery [7-9]. The aim of this article is to present our experience in treating primary SCCs of the subglottic larynx with RT alone or a combination of laryngectomy and either preoperative or postoperative RT.

\section{Methods}

Eighteen unselected patients (16 males and 2 females) were treated with curative intent for subglottic SCCs with RT alone or combined with surgery at the University of Florida between 1977 and 2009 (Table 1). The definition of the subglottis for this study was $1 \mathrm{~cm}$ below the apex of the ventricle for the superior border and the lower margin of the

Table 1 Patient population

\begin{tabular}{lccr}
\hline Parameter & RT alone & Surgery + RT & Total \\
\hline Gender & & & \\
Male & 10 & 6 & 16 \\
Female & 2 & 0 & 2 \\
T-stage & & 1 & \\
$\mathrm{~T}_{1}$ & 3 & 0 & 4 \\
$\mathrm{~T}_{2}$ & 2 & 1 & 2 \\
$\mathrm{~T}_{3}$ & 0 & 4 & 1 \\
$\mathrm{~T}_{4}$ & 7 & & 11 \\
$\mathrm{~N}_{\text {-stage }}$ & 11 & 4 & 15 \\
$\mathrm{~N}_{0}$ & 1 & 1 & 2 \\
$\mathrm{~N}_{1}$ & 0 & 1 & 1 \\
$\mathrm{~N}_{2 \mathrm{~B}}$ & & & \\
\hline
\end{tabular}

$R T$ radiotherapy cricoid cartilage for the inferior border. Patients with primary glottic neoplasms with subglottic extension were excluded from the study.

Eleven patients were treated with RT alone; seven were treated with surgery and RT. Four patients received surgery and postoperative RT, while three received preoperative RT followed by surgery. The AJCC T-stage distribution was as follows: $\mathrm{T}_{1}, 4$ patients; $\mathrm{T}_{2}, 2$ patients; $\mathrm{T}_{3}, 1$ patient; and $\mathrm{T}_{4}$, 11 patients. Two patients presented with $\mathrm{N}_{1}$ neck disease, and one patient presented with $\mathrm{N}_{2 \mathrm{~B}}$ neck disease. No patients presented with distant metastases.

The median dose for patients treated with definitive RT was 74.0 Gy (range, 57.5-75.0 Gy). The median dose for patients treated postoperatively was 58.3 Gy (range, 56.6$66.0 \mathrm{~Gy}$ ). The doses for the three patients treated preoperatively were $47.2,50.4$, and $60.0 \mathrm{~Gy}$, respectively. Nine patients were treated once daily, and nine patients received twice-daily fractionation. Patients treated for $\mathrm{T}_{1}-\mathrm{T}_{2} \mathrm{~N}_{0}$ cancers were irradiated with fields directed at the larynx with a 1-2-cm margin. Those with $\mathrm{T}_{3}-\mathrm{T}_{4}$ and/or node-positive cancers were irradiated to the primary site and both sides of the neck, as were patients treated with pre- or postoperative RT. All surgical interventions were total laryngectomies, with three of the six patients undergoing laryngectomy also undergoing bilateral neck dissections. All patients with nodal disease were recommended to undergo surgery and adjuvant radiotherapy, but one patient with $\mathrm{N} 1$ disease elected to have radiotherapy alone. No patients received adjuvant chemotherapy.

Patients were followed with periodic physical examinations, including fiberoptic endoscopy when necessary, thyroid function tests, and chest radiographs. Periodic head and neck computed tomographic scans were obtained as part of the follow-up process for patients treated for $\mathrm{T}_{3}-\mathrm{T}_{4}$ and/or node-positive cancers.

All statistics were computed using SAS software (Cary, NC). Survival estimates for endpoints were attained using the Kaplan-Meier product limit method [10]. Local control was defined as complete regression of the primary tumor with no evidence of local recurrence on subsequent physical examinations, radiographic studies, or both until the last follow-up or death. Death from intercurrent disease was defined as death without evidence of recurrent cancer. Median follow-up was 3.3 years (range, $0.9-17.0$ years); median follow-up for living patients was 7.2 years (range, 4.117.0 years).

\section{Results}

Local control is depicted in Table 2. Of the three patients who failed locally, all four had $\mathrm{T}_{4} \mathrm{~N}_{0}$ disease, and all had an attempted salvage procedure. Successful salvage was 
Table 2 Local control

\begin{tabular}{lccl}
\hline T-Stage & RT Alone & Surgery + RT & Total \\
\hline $\mathrm{T}_{1}$ & $3 / 3$ & $1 / 1$ & $4 / 4$ \\
$\mathrm{~T}_{2}$ & $2 / 2$ & $0 / 0$ & $2 / 2$ \\
$\mathrm{~T}_{3}$ & $0 / 0$ & $1 / 1$ & $1 / 1$ \\
$\mathrm{~T}_{4}$ & $5 / 7$ & $3 / 4$ & $8 / 11$ \\
Total & $10 / 12$ & $4 / 6$ & \\
\hline
\end{tabular}

$R T$ radiotherapy

achieved in one of the three patients. The local-regional control pattern mirrored that of local control. The only difference between local control and local-regional control was that one patient, who had successful local salvage therapy, did not have a successful regional salvage. The overall rate of laryngeal voice preservation for the series was $10(56 \%)$ of 18 patients.

At 5 years, overall survival was $44 \%$, and cause-specific survival was $66 \%$ (see Fig. 1). Three patients, two with $\mathrm{T}_{4} \mathrm{~N}_{0}$ disease and one with $\mathrm{T}_{3} \mathrm{~N}_{2 \mathrm{~B}}$ disease (see Table 2), developed distant metastases after treatment. Two of these patients, one with $T_{4} \mathrm{~N}_{0}$ disease and the one with $\mathrm{T}_{3} \mathrm{~N}_{2} \mathrm{~B}$ disease, were locally controlled.

No grade 2 or 3 complications were observed. Most patients, who received RT alone, reported transient hoarseness and regained normal speaking abilities within 6 months.

\section{Discussion}

Primary subglottic cancer was described in the literature as early as the nineteenth century, but today, there is still a lack of consensus on the appropriate management. Review studies, in the $1970 \mathrm{~s}$, reported 5-year overall survival rates between 36 and $42 \%$ [11]. More recent studies have suggested that the 5-year overall survival of patients with

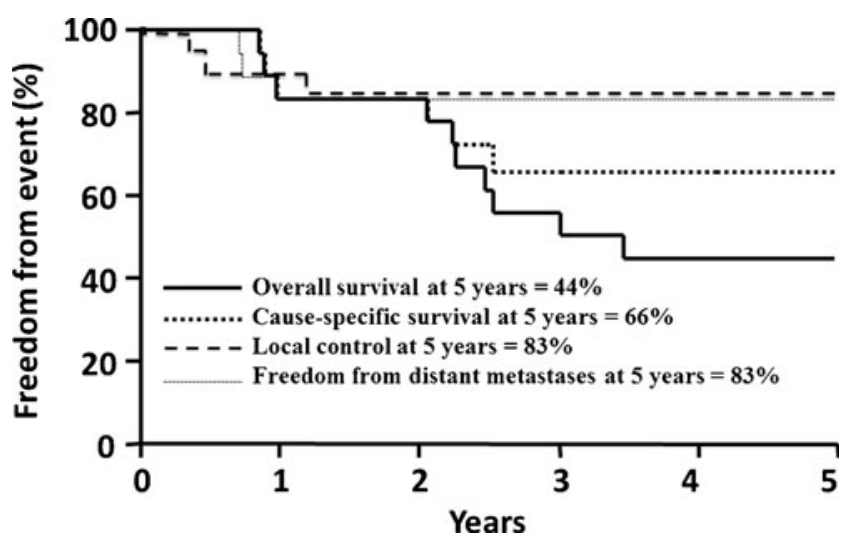

Fig. 1 Five-year rates of overall survival, cause-specific survival, local control, and freedom from distant metastasis primary subglottic carcinoma is closer to $50 \%$ [7, 12]. Our series reported a 5 -year overall survival of $44 \%$ and a cause-specific survival of $66 \%$, indicating that many of these patients had multiple medical comorbidities and died from intercurrent disease. Our 5-year cause-specific survival rate of $66 \%$ is in line with published studies by Paisley et al. [7] and Santoro and co-workers [8].

Due to the absence of symptoms early in the disease course, subglottic cancer is likely to be locally advanced at presentation $[3,8,13]$. Two thirds of patients in our series had advanced-stage disease at diagnosis, which was comparable to studies by Santoro et al. [8], who reported advanced disease in $65 \%$ of patients, and Shaha and Shah [14], who reported advanced disease in $75 \%$ of patients.

Recommendations for treating early-stage disease have varied from using RT alone $[3,4,7,9]$ to using combination therapy of surgery and adjuvant RT [8, 12]. Our series showed an excellent local-control rate of $100 \%$ for earlystage disease treated with RT alone. Variations also exist in the recommendations for managing late-stage disease. While some suggest RT alone [4, 7], most series indicate that combined surgery and adjuvant RT is most effective [1, $3,8,9,15]$. Our series showed that late disease could be locally controlled well with surgery and adjuvant RT (80 \%) as well as RT alone (71\%). A caveat is that those treated with RT alone were selected and thus had, on average, less advanced cancers.

Based on our findings, our current recommendations are to treat early-stage disease without nodal involvement $\left(\mathrm{T}_{1}-\right.$ $\mathrm{T}_{2} \mathrm{~N}_{0}$ ) with definitive RT with larynx-only fields to between 63 and 65.25 Gy at 2.25 Gy per fraction. If early-stage lesions exhibit subglottic extension greater than $1 \mathrm{~cm}$, elective neck node RT is added, and the use of either hyperfractionation or accelerated fractionation is employed. For patients with $T_{3}-T_{4}$ primary tumors less than $3.5 \mathrm{~cm}^{3}$, definitive RT (via hyperfractionation or accelerated fractionation) is used with concurrent weekly cisplatin $30 \mathrm{mg} / \mathrm{m}^{2}$. For patients with $\mathrm{T}_{3}-\mathrm{T}_{4}$, primary tumors greater than $3.5 \mathrm{~cm}^{3}$, total laryngectomy with neck dissection is undertaken followed by postoperative RT. Postoperative RT dose depends on the resection margins: 60 Gy for negative margins, 66 Gy for microscopically positive margins, and 70 Gy for gross-residual disease. Patients are treated at $2 \mathrm{~Gy}$ per once-daily fraction. Patients receive concomitant chemotherapy with postoperative RT if either positive margins or extracapsular extension in a positive node.

Patients with positive nodes treated with RT alone are evaluated post-RT with a CT scan and/or positron emission tomography-CT, and those who have a complete response are followed. Those with an incomplete response undergo a planned neck dissection. Patients with positive nodes treated surgically undergo a neck dissection in conjunction with the laryngectomy followed by postoperative RT. 


\section{Conflict of interest None.}

\section{References}

1. Ferlito A, Rinaldo A (2000) The pathology and management of subglottic cancer. Eur Arch Otorhinolaryngol 257(3):168-173

2. Muntz H, Sessions D (1985) Surgery for laryngopharyngeal and subglottic cancer. In: Bailey B, Hiller H (eds) Surgery of the larynx. Saunders, Philadelphia, pp 311-314

3. Guedea F, Parsons JT, Mendenhall WM, Million RR, Stringer SP, Cassisi NJ (1991) Primary subglottic cancer: results of radical radiation therapy. Int J Radiat Oncol Biol Phys 21(6):1607-1611

4. Warde P, Harwood A, Keane T (1987) Carcinoma of the subglottis. Results of initial radical radiation. Arch Otolaryngol Head Neck Surg 113(11):1228-1229

5. Silvestri F, Bussani R, Stanta G, Cosatti C, Ferlito A (1992) Supraglottic versus glottic laryngeal cancer: epidemiological and pathological aspects. ORL J Otorhinolaryngol Relat Spec 54(1):43-48

6. AJCC (2010) Laryngeal. In: Edge SB, Byrd DR, Compton CC, Fritz AG, Greene FL, Trotti A (eds) AJCC cancer staging manual, 7th edn. Springer, New York, pp 57-67
7. Paisley S, Warde PR, O'Sullivan B, Waldron J, Gullane PJ, Payne D, Liu FF, Bayley A, Ringash J, Cummings BJ (2002) Results of radiotherapy for primary subglottic squamous cell carcinoma. Int $\mathrm{J}$ Radiat Oncol Biol Phys 52(5):1245-1250

8. Santoro R, Turelli M, Polli G (2000) Primary carcinoma of the subglottic larynx. Eur Arch Otorhinolaryngol 257(10):548551

9. Garas J, McGuirt WF Sr (2006) Squamous cell carcinoma of the subglottis. Am J Otolaryngol 27(1):1-4

10. Kaplan EL, Meier P (1958) Nonparametric estimation from incomplete observations. J Am Stat Assoc 53:457-481

11. Vermund H (1970) Role of radiotherapy in cancer of the larynx as related to the TNM system of staging. A review. Cancer 25 (3):485-504

12. Dahm JD, Sessions DG, Paniello RC, Harvey J (1998) Primary subglottic cancer. Laryngoscope 108(5):741-746. doi:10.1097/ 00005537-199805000-00022

13. Harrison DF (1971) The pathology and management of subglottic cancer. Ann Otol Rhinol Laryngol 80(1):6-12

14. Shaha AR, Shah JP (1982) Carcinoma of the subglottic larynx. Am J Surg 144(4):456-458

15. Haylock BJ, Deutsch GP (1993) Primary radiotherapy for subglottic carcinoma. Clin Oncol (R Coll Radiol) 5(3):143-146 